Federal Reserve Bank of Dallas

Globalization and Monetary Policy Institute

Working Paper No. 244

http://www.dallasfed.org/assets/documents/institute/wpapers/2015/0244.pdf

\title{
World Steel Production: A New Monthly Indicator of Global Real Economic Activity ${ }^{*}$
}

\author{
Francesco Ravazzolo \\ Free University of Bozen/Bolzano \\ Joaquin L. Vespignani \\ University of Tasmania and Centre for Applied Macroeconomic Analysis \\ June 2015 \\ Revised: July 2017
}

\begin{abstract}
In this paper we propose a new indicator of monthly global real economic activity, named world steel production. We use world steel production, OECD industrial production index and Kilian's rea index to forecast world real GDP, and key commodity prices. We find that world steel production generates large statistically significant gains in forecasting world real GDP and oil prices, relative to an autoregressive benchmark. A forecast combination of the three indices produces statistically significant gains in forecasting world real GDP, oil, natural gas, gold and fertilizer prices, relative to an autoregressive benchmark.
\end{abstract}

JEL codes: E1, E3, C1, C5, C8

\footnotetext{
* Francesco Ravazzolo, Free University of Bozen/Bolzano, Faculty of Economics and Management, Universitätsplatz 1, 39100 Bozen-Bolzano, Italy. +39-0471-013133. francesco.ravazzolo@unibz.it. Joaquin Vespignani, Tasmanian School of Business and Economics, University of Tasmania, Centennial Building, Level 1, Room 114, Private Bag 85, Hobart Tasmania 7001, Australia. +61-3-6226-2802. www.joaquinvespignani.com. The views in this paper are those of the authors and do not necessarily reflect the views of the Federal Reserve Bank of Dallas or the Federal Reserve System.
} 


\section{Introduction}

In empirical analysis often an indicator of global real economic activity is used to represent the world economy. World real GDP, measured at quarterly frequency in United States (US) dollars using purchasing power parity, is broadly accepted and frequently used as a measure of global real economic activity. However, there is a lack of degrees of freedom associated with quarterly data and measures errors associated with the conversion of domestic real GDP to the US currency. To address this issue, economic modellers commonly turn to a monthly indicator of global real economic activity. Consequently, several monthly indicators have been used in the literature to measure real economic activity (at both country and global level). ${ }^{1}$

World real GDP is estimated by the International Monetary Fund (IMF). ${ }^{2}$ Besides some measurement problems, this index is heavily used by international organizations such as the IMF, World Bank (WB) and Bank for International Settlements. Central banks also report this index in statements of monetary policy and it is generally accepted as the main measure of global outputs. Consequently, predicting world real GDP with monthly indicators is important for country-specific forecasts and policymakers. ${ }^{3}$ Similarly, forecasting commodity prices help to understand future economic performance, inflation and level of production (see for example Groen and Pesentu (2011)).

The most widely used indicators of monthly real economic activity are: the Organisation for Economic Co-operation and Development (OECD) industrial production, taken from Main Economic Indicators (MEI), and Kilian’s rea index. For example, among

\footnotetext{
${ }^{1}$ We concentrate our analysis on observable indicators and do not consider unobservable global factors, such as global factors extracted by large datasets.

${ }^{2}$ The aggregation of many countries' GDP in a unique index generally presents measurement problems associated with the conversion to a unique currency (US dollar) and relays on the collaboration of many statistical agencies. See for example Chen and Ravallion (2010).

${ }^{3}$ The use of world real GDP is not limited to central banks and international banks. It is also the core global indicator in many research areas including: income, inequality and poverty studies. See, for example, Chen and Ravallion (2010) or Deaton (2005).
} 
others, Mullineaux (1980), Grilli and Roubini (1996), Bernanke et al. (1997), Kim (2001), and Kim and Roubini (2001) have used industrial production as a proxy for real economic activity for large developed economies. Similarly, Mackowiak (2007) measured real economic activity at country level for emerging economies using industrial production. ${ }^{4}$ Not without controversy, the index of industrial production for aggregated OECD economies has been widely used as a proxy for global real economic activity. For example, Gerlach (1988) uses both industrial production index for OECD countries and US industrial production as a proxy for global real economic activity in the study of world business cycles under different exchange rate regimes. Furthermore, Ciccarelli and Mojon (2010) use the industrial production index for OECD economies in studying global inflation.

Kilian (2009) developed an index of global real economic activity (rea) using data of dry cargo single voyage ocean freight rates. Kilian's rea index is not a proxy for global Real GDP. Since 2009, this indicator has become a popular choice to represent global real economic activity, in particular for oil price studies. Among others, Apergis and Miller (2009) model the effect of oil shocks on different country stock prices using this index. Basher et al. (2011) use this index to study the relationship between oil prices, exchange rates and emerging stock markets. Vespignani and Ratti (2013) build a SVAR model to describe the influence of global liquidity on oil prices using Kilian’s rea index as a proxy for global real economic activity. Baumeister and Kilian (2013) use this index, in conjunction with other variables, to forecast real oil prices.

\footnotetext{
${ }^{4}$ For large developed economies: Mullineaux (1980) in studying the relationship between unemployment, output and inflation for the US; Grilli and Roubini (1996) in studying liquidity models for G7 economies; Bernanke et al. (1997) in studying the effect of oil price shocks for the U.S economy; Kim (2001) in addressing international transmissions of monetary shocks for non-US G6 economies; and Kim and Roubini (2001) in developing a model for exchange anomalies for non-US G7 economies. For emerging economies: Mackowiak (2007) studies the transmission mechanism of US shocks to emerging economies, including the following countries Chile, Hong Kong, Korea, Malaysia, Mexico, Philippines, Singapore and Thailand.
} 
We extend the indicator set with a proposed new indicator: world steel production. Steel is an important input component of global real economic activity. We show strong evidence of the predictability power of world steel production in forecasting; world GDP, oil and fertilizer prices. In particular, world steel production generates statistically significant gains of up to 34\%, 6.50\% and 8.40\% in forecasting world real GDP, oil and fertilizer prices (respectively), relative to an autoregressive benchmark. In a forecast combination exercise using world steel production, OECD IP and Kilian's rea index produce statistically significant gains of up to $40 \%, 11.40 \%$ and $4.60 \%$ in forecasting world real GDP, natural gas and fertilizer prices (respectively), relative to an autoregressive benchmark.

The remainder of the paper is organised as follows: Section 2 provides a review of current indicators of global real economic activity used in the literature. Section 3 characterise world steel production monthly series. In sections 4 and 5, we forecast world real GDP, and individual's commodity prices (respectively). Section 6 concludes.

\section{Current indicators of global real economic activity}

In this section we describe two popular choices of monthly indicators of global real economic activity: OECD industrial production and Kilian's rea index. OECD industrial production is available from the OECD Main Economic Indicators (MEI) database from January 1975 to the present. The popularity of using this index to represent global real economic activity can be partially attributed to the fact that prior to 2009 there were few alternative time series of reasonable length that were representative of monthly global real economic activity. This index is constructed with data from 34 OECD countries. ${ }^{5}$ According to the OECD MEI definition:

\footnotetext{
${ }^{5}$ These countries are: Australia, Austria, Belgium, Canada, Chile, the Czech Republic, Denmark, Estonia, Finland, France, Germany, Greece, Hungary, Iceland, Ireland, Israel, Italy, Japan, Korea, Luxembourg, the Netherlands, New Zealand, Norway, Mexico, Poland, Portugal, the Slovak Republic, Slovenia, Spain, Sweden, Switzerland, Turkey, the United Kingdom and the United States.
} 
Area totals for industrial production are annually chain-linked Laspeyres indices. The weights for each yearly link are based on the previous year's world real GDP in construction adjusted by GDP purchasing power parity.

The use of this index as a proxy for global real economic activity relies on two assumptions. The first assumption is that the industrial sector is a good representation of the full economy. The second assumption is that the OECD economies are representative of the world economy. Prior to 1990, both assumptions were reasonable, as manufacturing sectors were a large part of most economies and economic growth was concentrated in developed economies. However, most recent empirical evidence indicates a diversion between industrial production and other measures of economic activity such as real GDP. For example, Steindel (2004) argues that the relationship between industrial production and the goods output component of real GDP has diverged significantly since the 2001 recession in the US. Steindel (2004) attributes this departure to the growth of imports and the increase of services inputs of all goods. Similarly, Herrera et al. (2011) attribute the possible divergence of GDP and industrial production to two factors. Firstly, real GDP is a measure of the valued added in the economy, while industrial production measures gross output; and secondly, industrial production excludes services whose contribution to real GDP has increased over time in the US.

In Kilian's (2009) influential study on oil prices, Kilian disputes the use OECD industrial production indicator as a proxy for global real economic activity. Kilian's main critique is that OECD industrial production excludes emerging economies in Asia such as China and India, whose demand for industrial raw materials is thought to be fuelling the surge in industrial commodity and oil prices since $2002 .{ }^{6}$ Similarly, with reference to global output,

\footnotetext{
${ }^{6}$ Support for this view can also be found in Hamilton (2013) and Kilian and Hicks (2013).
} 
Engel and Rogers (2006) note that in terms of purchasing power parity, the combined real GDP of emerging economies such as Brazil, China, India, Indonesia, Korea, Mexico, Philippines, and Thailand was 2.43 times the real GDP of the US. Crucini et al. (2011) also observe that the share of global output of G7 economies has declined in recent decades while the share of emerging economies such as China and India has increased. Kose et al. (2012) indicate that emerging market economies (specifically China and India) have become major contributors to world output over the period 2003-2007. Kilian (2009) also questions the lack of clarity in which the weights of the OECD industrial index are defined, given different exchange rates across countries.

Focusing on the study of oil prices, Kilian (2009) proposed a monthly measure of global real economic activity by constructing an index using dry cargo single voyage ocean freight rates from "Shipping Statistics and Economics". Kilian constructs this index using monthly data published by Drewry Shipping Consultants Ltd from the period January 1968 to the present based on various bulk dry cargoes prices, including grain, oilseeds, coal, iron ore, fertilizer and scrap metal. When modelling international commodity prices or business cycles, an important advantage of this series is that it has a long span, being built from 1968 at a monthly frequency.

Klovland (2004) argues that world real economic activity is by far the most important influential variable in determining demand for sea transport. Empirically, Klovland (2004) demonstrates that from 1850 to the First World War (WWI), cycles in real economic activity can explain the short-term behaviour of shipping freight rates. ${ }^{7}$ In line with this view, Kilian

\footnotetext{
${ }^{7}$ For the period preceding WWI, Tinbergen (1959), Isserlis (1938) and Meuldijk (1940) also document the positive correlation between freight rates and real economic activity. Stopford (1997) studies this relationship from 1872 to 1989, finding similarities in cyclical peaks and troughs between shipment and business cycles.
} 
(2009) argues that this dry cargo single freight rate index is designed to capture changes in the demand for industrial commodities in global markets.

Kilians's rea index is constructed with quotes for different commodities, routes and ship sizes. However, due to limitations in the data, the index uses equal weights for both commodities and routes. Equal weighting may be a source of bias across time as both individual commodities and routes are expected to significantly fluctuate across time. ${ }^{8}$ The shift in global demand for commodities (and potentially the shift in global routes), has been documented by several authors: Kilian (2008), Kilian (2009), Kilian and Hicks (2013) and Hamilton (2013) attributes the increase in oil prices since 1997 to the unprecedented increase in consumption of oil from newly industrialised economies. ${ }^{9}$ Also supporting the shift in global demand for commodities, Barsky and Kilian (2004) and Humphreys (2010) observe that industrialisation increases demand for metals substantially and that developments in the economies of Brazil, Russia, India, China (BRIC) is the main factor behind the boom in metal prices from 2003 to 2008. Radetzki (2006) argues that since 2004, the increase in global demand for commodities was the highest on record over the preceding 30 years and that this was a consequence of increases in demand from developing Asian economies. The unprecedented increase in demand from Asian developing economies (particularly China and India) observed since 1997 cannot be properly captured when using equal weights, see for example Kilian and Hicks (2013) and Aastveit at al. (2014).

Kilian’s rea index also uses equal weights for different shipping prices, including grain, oilseeds, coal, iron ore, fertilizer, and scrap metal. However, the relative consumption and

\footnotetext{
${ }^{8}$ Note that the structure of Kilian's rea index is similar to a factor model. Factor models are also constructed from growth rates. It has been shown that in many applications ignoring cointegration in the latter context has little effect.

${ }^{9}$ This contrasts with the period 1973-1996, when the main factor affecting the price of oil was supply shocks originating from Organization of the Petroleum Exporting Countries (OPEC) producers according to Hamilton (2013).
} 
prices of these commodities may shift across time. These inter-temporal changes in relative consumption of commodities have been well documented by several studies: Stout (2012) shows that oil consumption increased more rapidly than coal consumption between 1970 and 1980 but at a substantially slower rate than between 1980 and $1995 .^{10}$

\section{World steel production: a new indicator of global real economic activity}

Crude steel is a key input for many industries, including but not limited to: construction, transport, energy, packaging, home goods and agriculture. Consequently a world measure of steel production is expected to track the global real economic activity fairly well. ${ }^{11}$ The World Steel Association (WSA) has published monthly figures for world steel production since January 1990. The series aggregates the production of crude steel for 65 countries, which was estimated to account for $98 \%$ of world steel production in $2013 .{ }^{12}$ The unit of measurement is thousands of tonnes. The data are collected by the WSA from several sources, including WSA member companies, national statistics offices and regional steel industry associations. The data is provided by the WSA for the public only in hardcopy, therefore the data was entered manually in a spreadsheet by the authors. The weighting problem associated with the OECD

\footnotetext{
${ }^{10}$ This view is also supported by the International Monetary Fund (IMF) World Economic Outlook (2014), which indicates that world primary energy consumption (oil, coal and gas) has grown much faster than metal and food consumption since 2001.

${ }^{11}$ According to the WSA, steel is a major input for the following goods: Construction (low- and high-rise buildings, housing, modular buildings, retail, industrial, education and hospital buildings, sports stadia, stations, reinforcing bars for concrete, bridge deck plates, piers and suspension cables, harbours, cladding and roofing, office, tunnels, security, coastal and flood defences), Transport (car bodies, engine components, wheels, axles, trucks, transmissions, trains, rails, ships, anchor chains, aircraft undercarriages, jet engines components), Energy (oil and gas wells and platforms, pipelines, electricity power turbine components, electricity pylons, wind turbines), packaging ( food and beverage cans, promotional materials, aerosols, paint and chemical containers, bottle tops and caps), home goods (domestic appliances such as fridges, washing machines, ovens and microwaves, sinks, radiators, cutlery, hi-fi equipment, razors, pins), agriculture (farm vehicles and machinery, storage tanks, tools, structures, walkways, protective equipment).

12 The countries (by continent) are: European Union: Austria, Belgium, Bulgaria, Croatia, the Czech Republic, Finland, France, Germany, Greece, Hungary, Italy, Luxembourg, the Netherlands, Poland, the Slovak Republic, Slovenia, Spain, Sweden, the United Kingdom, Bosnia-Herzegovina, Macedonia, Norway, Serbia, Turkey, Belarus, Kazakhstan, Moldova, Russia, Ukraine, Uzbekistan, other European countries. North America; Canada, Cuba, El Salvador, Guatemala, Trinidad Tobago, the United States. South America; Argentina, Brazil, Chile, Colombia, Ecuador, Paraguay, Peru, Uruguay, Venezuela. Africa; Algeria, Egypt, Libya, Morocco, South Africa,. Asia; China, India, Japan, South Korea, Taiwan, Iran, Qatar, Saudi Arabia the United Arab Emirates. Oceania; Australia and New Zealand.
} 
industrial production index and Kilian's rea index does not apply to steel production, as the latest index is aggregated on monthly basis. Another advantage is that the series does not require deflating as steel production is a real variable.

Additionally, different rates of growth among countries do not bias this indicator as crude steel production is a relatively homogenous good that is traded freely around the world. Changes in productivity across countries are not problematic for this indicator (as may be the case for OECD industrial production index), given that production of steel generally moves from more expensive to cheaper producers (countries). For example, from 1990 to 2013, Chinese steel production grew by a factor of 10.8 while the US steel production remained relatively unchanged for the full sample.

In Figure 1, world steel production and world real GDP is plotted from Q1 1990 to Q3 2013. ${ }^{13}$ This figure show that from the start of series in 1990-2002, both series track the last part of the period so called "the Great Moderation" well (the period where major economic variables such as real GDP growth and inflation began to decline in volatility) and the mild recession observed in the US in 2001, which negatively impact the global economy. From 2002, both series grew rapidly until the GFC, and this period of rapid growth is explained by the acceleration of economic growth and increasing demand for commodities from emerging economies. This fast growth period is also observed in world real GDP and global commodity prices. In 2008, the GFC took place and world steel production decreases rapidly in line with the decline observed by commodity prices and world real GDP. After this negative shock, world steel production recovers fast in 2009. Afterwards the slope of world steel production is flatter than in the period 2001-2008. This is consistent with the slower pace observed in world real GDP.

\footnotetext{
${ }^{13}$ Data for world real GDP was downloaded from IMF IFS database and the series ends in 2013.
} 
In Figure 2; oil, natural gas, gold, and fertilizer prices are plotted. We index to normalize the series for comparison purposes where January 1990=100. Although commodity prices are more volatile than world steel production (as note in this figure), similar patterns are observed. In particular, in the last part of the great moderation period (1990-2001), the slope of most commodity prices is flat. Natural gas seems to be more volatile that other commodities, showing picks in 2001, 2003, 2006 and 2008. The pick on gold prices observed in 2008, respond to the "save heaven" status this commodity has, as savings moved from financial instruments to gold during the global financial crisis. Similarly, to world steel production, a upward trend is observed from 2001 to 2008, in line with the periods of unprecedented economic growth observed in world economy and driven by emerging countries demand (see for example Kilian and hicks (2013)).

The use of a closely-related commodity like steel production as an indicator of real economic activity was first proposed by Macaulay (1938), who creates a series of pig iron production in the US. This indicator was used as a measure of real economic activity before 1936 (when other series were not available) by several authors including Zarnowitz (1987), Gorton (1988) and Calomiris and Hubbard (1989). Miron and Romer (1990) argue that the main problem with this indicator is that it is based on only one commodity, whereas in most settings a more broadly based indicator would be desirable. This disadvantage also applies to world steel production. In addition, another drawback of world steel production, when compared with Kilian's rea index and OECD industrial production is that this index series starts only in early 1990s. Accordingly, it is unable to explain any phenomena prior to this time. ${ }^{14}$

\footnotetext{
${ }^{14}$ We have also investigated the CPB World Trade Monitor (WTM) data. This index is constructed by the CPB (Central Planning Bureau) Netherlands Bureau for Economic and contains monthly seasonally-adjusted world trade data for 81 countries worldwide, which by 2010 jointly accounted for $99 \%$ of world trade. Similar to world steel production, the aggregation weights (value series are simply added in current dollar prices) and the fact that this data is reported at country, regional and global levels constitute very important features. The main drawbacks are that the index starts only in 1990 and it is released with a two month publication lags. Our econometric
} 


\section{Forecasting world real GDP}

\subsection{Exercise set-up}

In this section we evaluate the out-of-sample predictive power of these indices in forecasting world real GDP. Inoue and Kilian (2004) examine the question of in-sample versus out-ofsample testing of predictability, motivated by the finding that positive in-sample evidence of predictability is often not associated with out-of-sample predictability. Ashley, Granger and Schmalensee (1980) claim that in-sample inference without out-of-sample verification is likely to be spurious, with an out-of-sample approach inherently involving less overfitting. Inoue and Kilian (2004) assert that this argument is not compelling since there is ample opportunity for the researcher to data mine in a simulated out-of-sample study, and because data snooping adjustments can be made to both tests. Moreover, we provide further evidence of a growing literature on out-of-sample nowcasting and forecasting of global real GDP: see e.g. Ferrara and Marsilli (2014), Golinelli and Parigi (2014) and Rossiter (2010).

We split the full quarterly sample 1991Q1-2013Q1 into two periods: an initial insample period 1991Q1-1999Q4 and the out-of-sample (OOS) period 2000Q1-2013Q1. ${ }^{15} \mathrm{We}$ use a recursive window to estimate the models and produce the forecasts over the different vintages. For each of the 53 OOS values, we produce from 1- to 8-step ahead forecasts using several different models based on the indicators of global real economy. Precisely, we apply the following models:

$$
d G G D P_{t}=\alpha+\beta d G G D P_{t-1}+\gamma X_{i, t-1}+\varepsilon_{t}
$$

approach and the forecasting exercise in section 4 and 5 indicate that an index based on the world steel production provides superior statistics than the index based on world Trade.

${ }^{15}$ Our sample split allocates a relative long in-sample set of values for the initial vintages in order to mitigate the parameter uncertainty. Therefore, our recursive window assumption implies parameter uncertainty vanishes in the limit, supporting Diebold-Mariano type comparison as we do. We also investigate longer out-of-sample periods by starting the forecasting exercises 1999Q1 and 1998Q1, and results were qualitatively similar. 
where $X_{i, t-1}$ is one of the three indicators of global real economy activity, that is Kilian's rea index, OECD industrial production and world steel production; and $\varepsilon_{t}$ is the error term with zero mean and $\sigma^{2}$ variance. Each model produces an $h$-step ahead forecast of detrended world real GDP, $d G G D P_{t+h}$, our preferred measure of value added GDP, as:

$$
d \widetilde{G G D} P_{i, t+h}=a+b d G G D P_{t}+c X_{i, t}
$$

where $a, b$ and $c$ are the OLS estimates of unknown parameters $\alpha$ and $\beta$ in Equation (1). ${ }^{16}$ The indicators are monthly variables and we convert them to quarterly observation $X_{i, t}$ using the most updated available information. ${ }^{17}$ The release date of data varies between series. The timeliest indicator is the world steel production that is published with one-month delay. OECD industrial production is published with longer delays; and the Kilian's rea index depends on the author publishing the new information. We assume OECD industrial production and Kilian's rea index is available with 3-month delays, even if there is evidence of longer publication delay. World real GDP is also published with delay, but the length of delay varies. In our exercise, we assume the release to be at the end of month 3 of the quarter and world real GDP from the previous quarter is just released. However, world steel production in month 2 of the quarter is available; whereas the most up-to-date information of the OECD industrial production and the Kilian's rea index refers to month 3 of the previous quarters. ${ }^{18}$ World steel production is never revised; we ignore revisions for the other two indices and for world real GDP. Accordingly, our analysis is a (pseudo) real-time forecasting exercise where the 1-step ahead forecast corresponds to nowcast.

\footnotetext{
${ }^{16}$ We fix the autoregressive lag to 1 because this model outperforms models with more lags. Irrespectively, results are qualitative similar for models with more autoregressive lags. Moreover, the linear framework in Equation (2) ignores that indicators are available at higher frequency than world real GDP. We leave for future research to investigate regression methods that allow for estimation with mixed frequency data, such as MIDAS models, see e.g. Ferrara and Marsilli (2014).

${ }^{17}$ Since the four indicators are indices, the last observation should contain all the history information.

${ }^{18}$ Results are qualitatively similar when indicators are lagged one-month further.
} 
We compare the three individual models to the AR(1) benchmark model where $\gamma=0$. Moreover, to account for the uncertainty with regard to choice of indicators, we apply forecast combination (FC) strategies:

$$
d \widetilde{G G D} P_{c, t+h}=\sum_{i} w_{i, t+h} d \widetilde{G G D} P_{i, t+h}
$$

where $w_{i, t}>0, \sum_{i} w_{i, t}=1$ are forecast combination weights. We consider two types of weights. First, we assume equal weights, $w_{i, t}=1 / 3$. We label it as FC_EW. Second, we compute the weights $w_{i, t}$ as the inverse SPE of model $i$ up to time $(t-1)$ for horizon $h \cdot{ }^{19} \mathrm{We}$ label it as FC_SPE. Timmermann (2006) discusses benefits of the two methods and provides several macroeconomic examples where the two methods provide accurate forecasts relative to other models.

Finally, we test for OOS population-level predictability via the Clark and West (2007) (CW) test. The test is based on a mean squared prediction error (MSPE) adjustment to account for noise induced in the OOS forecasts by way of estimation of parameters with zero population means under the null hypothesis that the benchmark model is the true DGP.

\subsection{Forecasting results}

Table 1 reports the OOS forecasting results for the different individual models and the forecast combinations. All the three indicators produce lower MSPE at 1-step ahead, in two cases they are statistically significant. However, only the Kilian's rea index and the world steel production generate lower MSPEs for most of the horizons and in the case of the world steel production these gains are statistically significant relative to the AR benchmark up to 1-year ahead. Gains are economically significant, ranging from $30 \%$ to $40 \%$.

\footnotetext{
${ }^{19}$ For the initial $h$ period where the realization is not available to compute the square prediction error, we use equal weights in the FC_SPE scheme too.
} 
The largest forecast improvements are, however, achieved by the forecast combination schemes. The reduction in MSPEs is for all the horizons and statistically significant up to 6steps ahead. The gains are very large and for the FC_SPE scheme that on average provides the most accurate results over all horizons the reduction in terms of MSPE is $40 \%$ and more than $10 \%$ at the longer horizons.

\subsection{Local performance}

The previous section does not provide evidence on how the OOS predictive content varies across the subsamples considered. We apply the Giacomini and Rossi (2010) fluctuation test. This test provides a more formal framework for addressing this question; see also Ravazzolo and Rothman (2013). The test is motivated by the notion that if the OOS performance of the two models is time-varying, averaging this movement over the OOS period will result in a loss of information. In Figures 3 and 4, we provide time series plots for the fluctuation test at $\mathrm{h}=1$ and $\mathrm{h}=8$, the two horizons with higher and lower predictability, at the $10 \%$ significance level using 28 quarters rolling windows of CW test statistics (for testing the benchmark model against the alternatives). If the value of the fluctuation test statistic is greater than the critical value at observation t, the null hypothesis that the benchmark model is the true model for the 7-year window ending at time $t$ is rejected.

Figure 3 confirms the predictive power of the forecast combinations, which deliver statistically superior predictability over the entire sample, and it also shows that the indicators reduce the predictability after the US financial crisis, with the exception of the steel production index, which delivers lower statistics at beginning of the sample. The combinations, in particular FC_SPE, exploit such differences and improve forecast performances. However, the predictability reductions of individual indicators for 8-step ahead in Figure 4 is substantial and even the combination schemes are not statistically significant anymore, in particular after 2009. 
OECD IP performs poorly for the entire sample. Bjørnland, Ravazzolo and Thorsrud (2016) discuss in a forecasting framework how the US financial crisis has been a global event, but the recovery has been different across countries and a global economic factor loses predictability from 2010.

\section{Forecasting commodity prices}

\subsection{Methodologies}

The second exercise focuses on predict commodity indices. In this exercise, four of the most traded commodities are forecasted using Kilian's rea index, OECD IP, and world steel production and forecast combinations are used. The commodities are oil prices, natural gas, gold, and fertilizer. Oil and natural gas are the two most-traded energy commodities; gold represents precious metals; and fertilizer is an agriculture commodity. ${ }^{20}$ The data is from World Bank.

We split the full monthly sample 1992M1-2013M12 into two periods: an initial insample period 1992M1-1999M12 and the out-of-sample (OOS) period 2000M1-2013M12. As in the previous exercise, we use a recursive window to estimate the models and produce the forecasts over the different vintages. For each of the 168 OOS values, we produce from 1- to 12-month ahead forecasts using several different models based on the indicators of global real economic activity. Precisely, we apply the following models:

$$
\Delta \log C_{s, t}=\alpha+\sum_{j=1}^{p} \beta_{j} \Delta \log C_{s, t-j}+\gamma X_{i, t-1}+\varepsilon_{t}
$$

\footnotetext{
${ }^{20}$ Note the advantage of using fertilizer prices over other agricultural products are that this commodity is storable; this is an advantage for forecasting exercises. Price data of perishable agricultural products may be subjected to specific product or geographic features that cannot be captured by global activity indices, see for example Ravazzolo, Sveen and Zahiri (2016).
} 
where $\Delta \log C_{s, t}$ is the $\log$ return of commodity index $s, s=1, \ldots, 6$ at time t; $p$ is the autoregressive lag; $X_{i, t-1}$ is one of the three indicators of global real economy activity, that is Kilian's rea index, OECD industrial production and world steel production; and $\varepsilon_{t}$ is the error term with zero mean and $\sigma^{2}$ variance. We choose the lag order $p$ by studying the Akaike Information Criterion (AIC) and Bayesian Information Criterion (BIC) and fix $p=6$ for all indices as both criteria indicate that such a number is optimal for three cases. Each model produces an $h$-step ahead forecast of the $\log$ return of commodity index $i, \Delta \log C_{i, t}$, as:

$$
\widetilde{\Delta \log C}_{s, t+h}=a+\sum_{j=1}^{p} b_{j} \Delta \log C_{s, t-j+1}+c X_{i, t}
$$

where $a, b_{j}$ and $c$ are the OLS estimates of unknown parameters $\alpha, \beta_{j}$ and $\gamma$ in Equation (5). The forecasting analysis is done in real time and timing of real activity economic indices corresponds to the GDP example.

We compare the three individual models to the $\operatorname{AR}(p)$ benchmark model and the forecast combination (FC) strategies, FC_EW and FC_SPE, we applied in the previous section. Also, we test for OOS population-level predictability by using the Clark and West (2007) (CW) test.

\subsection{Forecasting commodity prices results}

Table 4 presents the OOS forecasting results for the individual indicators of global real economic activity models, and forecast combinations for four different commodities for up to 12-step ahead (or months). The commodities are placed in the following order in Table 2: a) oil prices, b) natural gas, c) gold, and d) fertilizer. All the three indicators produce lower MSPEs in at least one of the twelve periods ahead reported for all commodities. In general, world steel production produces larger gains than OECD IP and Kilian's rea index relative to the AR benchmark for the forecasts of most commodities. 
In Table 2a) the largest gains in forecasting oil prices are observed for world steel production. In particular, Wold steel production produces gains at one, three and ten stepsahead of $1.60 \%, 4.50 \%$ and $6.50 \%$, respectively. The three coefficients are statistically significant at $10 \%$ level. The Kilian's rea index produces only gains of $1.20 \%$, ten months ahead but the coefficient is not statistically significant. OECD IP produces gains of $5.80 \%$ ten months ahead and this result is statistically significant at $10 \%$ level. The forecast combinations FC_EW and FC_SPE both provide MSPE reductions which are statistically significant at one period ahead of up to $1.50 \%$. They also provide economic gains at other horizons, for example a $4.60 \%$ reduction at ten months, but these are not statistically significant.

In Table 2b) results for the forecast of natural gas are presented. Both OECD IP and world steel production generate some forecast gains which are statistically significant, while Kilian's rea index results are all statistically insignificant. OECD IP produces the largest gains for all three indicators for the periods ahead: one, two, five and seven, being the relative improvements of $4.5 \%, 7.4 \%, 6 \%$, respectively over the benchmark AR process. Both FC_EW and FC_SPE, produce MSPE reductions at one, two, three, five, six months ahead. The maximum gains are observed at three months ahead and the gains are up to $6.3 \%$. At the 1 step ahead differences are significant at 5\% level.

In forecasting gold (Table 2c), the largest gains are observed for Kilian's rea index in the fourth and fifth steps ahead of $2.70 \%$ and $3.80 \%$ but not statistically significant. OECD IP presents statistically significant (at $10 \%$ level) gains of up to $2.70 \%$ ten months ahead. The forecast combinations, FC_EW and FC_SPE produce gains for the third, fourth, fifth, seventh, eighth, ninth months ahead. The maximum gain is $3 \%$ for the fourth and fifth month ahead over the AR benchmark model and they are significant at 5\% and 10\% respectively. 
In Table 2d), the forecasting properties of these three indicators are evaluated for fertilizer prices. Both OECD IP and world Steel production produce important gains for these commodities which are statistically significant. OECD IP produces gains of $6.20 \%$, 4\%, 4.80\%, $11.70 \%, 4.50 \%$ and $2.20 \%$ at three, four, five, six, nine and ten months ahead which are statistically significant at $5 \%$ or $10 \%$ levels. World steel production produces gains of $2.20 \%$, $1.90 \%, 6.80 \%, 8.40 \%, 4.90 \%$ and $2.60 \%$ at three, four, five, six, and twelve months ahead. The forecast combinations also generate sizeable gains for two, three, four, five, seven and eight months ahead of around 7.40\%, 5.10\%, 6.10\%, 10.4\%, 4.80\% and 3.10\%, respectively; at 3month ahead horizon such reduction is statically significant at $1 \%$.

\section{Conclusions}

In this paper, we propose the use of world steel production as a new monthly indicator of global real economic activity in applied studies. World steel can successfully be used to forecast world real GDP and key commodity prices. Precisely, world steel production generates statistically significant gains of up to 34\%, $8.40 \%$ in forecasting World real GDP and oil prices, relative to an autoregressive benchmark.

We also documented that a combination of the three indices, world steel production, OECD IP and Kilian's rea index, produces gains of up to $40 \%, 11.40 \%$ and $4.60 \%$ in forecasting world real GDP, natural gas, and fertilizer prices, relative to an autoregressive benchmark. Therefore, our results show that the three indices contain different information, in particular for commodity prices, and their combination improves forecast accuracy. 


\section{References}

Aastveit, K.A., Bjørnland, H.C. and Thorsrud, L.A., 2014. What drives oil prices? Emerging versus developed economies. Journal of Applied Econometrics, forthcoming.

Apergis, N. and Miller, S.M., 2009. Do structural oil-market shocks affect stock prices?, Energy Economics, 31(4), 569-575.

Ashley, R., Granger, C. W. J. and Schmalensee, R., 1980. Advertising and aggregate consumption: An analysis of causality. Econometrica 48 (5), 1149-1167.

Barsky, R.B. and Kilian, L., 2004. Oil and the macroeconomy since the 1970s. Journal of Economic Perspectives, 18(4), 115-134.

Basher, S.A., Haug, A.A. and Sadorsky, P., 2012. Oil prices, exchange rates and emerging stock markets. Energy Economics, 34(1), 227-240.

Baumeister, C. and Kilian, L., 2013. Forecasting the Real Price of Oil in a Changing World: A Forecast Combination Approach. Journal of Business and Economic Statistics (forthcoming).

Bernanke, B.S., Gertler, M. and Watson, M., 1997. Systematic monetary policy and the effects of oil price shocks. Brookings Papers on Economic Activity, 1, 91-142.

Calomiris, C.W. and Hubbard, R.G., 1989. Price flexibility, credit availability, and economic fluctuations: Evidence from the United States, 1894-1909. The Quarterly Journal of Economics, 104(3), 429-52.

Chen, S., and Ravallion, M., 2010. The Developing World is Poorer than We Thought, But No Less Successful in the Fight Against Poverty. The Quarterly Journal of Economics, 125 15771625.

Clark, T. and West, K., 2007. Approximately normal tests for equal predictive accuracy in nested models. Journal of Econometrics, 138 (1), 291-311.

Ciccarelli, M. and B. Mojon., 2010. Global inflation. The Review of Economics and Statistics, 92 (3), 524-535.

Crucini, M., Kose, A., and Otrok, C., 2011. What are the driving forces of international business cycles? Review of Economic Dynamics, 14(1), 156-175.

Deaton, A., 2005. Measuring Poverty in a Growing World (or Measuring Growth in a Poor World)," The Review of Economics and Statistics, 87 1-19.

Engel, C. and Rogers, J.H., 2006. The U.S. current account deficit and the expected share of world output. Journal of Monetary Economics, 53(5),1063-1093.

Ferrara, L. and Marsilli, C., 2014. Nowcasting global economic growth: A factoraugmentedmixed-frequency approach. Banque de France Document der Travail 515. 
Gerlach, H.MS., 1988. World business cycles under fixed and flexible exchange rates. Journal of Money, Credit and Banking, 20(4), 621-32.

Giacomini, R. and Rossi, B., 2010. Forecast comparisons in unstable environments. Journal of Applied Econometrics, 25 (4), 595-620.

Golinelli, R. and Parigi, G., 2013. Tracking world trade and GDP in real time. International Journal of Forecasting, 30(4), 847-862.

Gorton, G., 1988. Banking panics and business cycles, Oxford Economic Papers, 40(4), 75181.

Grilli, V. and Roubini, N., 1996. Liquidity models in open economies: Theory and empirical evidence. European Economic Review, 40, 847-859.

Groen, J.J., and Pesenti, P.A., 2011. Commodity Prices, Commodity Currencies, and Global Economic Developments, NBER Chapters, in: Commodity Prices and Markets, East Asia Seminar on Economics, 20, 15-42 National Bureau of Economic Research.

Hamilton, J.D., 2013. Historical oil shocks. In: Parker, R.E., Whaples, R.M., (Eds.), The Routledge Handbook of Major Events in Economic History. New York: Routledge Taylor and Francis Group, 239-265.

Herrera, A.M., Lagalo, L.G. and Wada, T., 2011. Oil price shocks and industrial production: Is The Relationship Linear? Macroeconomic Dynamics, 15(S3), 472-497.

Humphreys, D., 2010. The great metals boom: A retrospective. Resources Policy, 35, 1-13.

Inoue, A. and Kilian, L., 2004. In-sample or out-of-sample tests of predictability: Which one should we use? Econometric Reviews, 23 (4), 371-402.

Isserlis, L., 1938. Tramp shipping cargoes, and freights. Journal of the Royal Statistical Society, 101, 53-134. In Klovland (2004).

Kim, S., 2001. International transmission of U.S. monetary policy shocks: Evidence from VAR's. Journal of Monetary Economics, 48(2), 339-372.

Kim, S. and Roubini, N., 2000. Exchange rate anomalies in the industrial countries: A solution with a structural VAR approach. Journal of Monetary Economics, 45(3), 561-586.

Kilian, L., 2008. The economic effects of energy price shocks. Journal of Economic Literature, 46(4), 871-909.

Kilian, L., 2009. Not all oil price shocks are alike: Disentangling demand and supply shocks in the crude oil market. American Economic Review, 99(3), 1053-69.

Kilian, L. and Hicks, B., 2013. Did unexpectedly strong economic growth cause the oil price Shock of 2003-2008? Journal of Forecasting 32, 385-394. 
Klovland, J.T., 2004. Business cycles, commodity prices and shipping freight rates: Some evidence from the pre-WWI period. Paper presented at Workshop on market performance and the welfare gains of market integration in history, Florence, Italy.

Kose, M.A., Otrok, C. and Prasad, E., 2012. Global business cycles: Convergence or Decoupling? International Economic Review, 53(2), 511-538.

Macaulay, F. (1938). The movements of interest rates, bond yields, and stock prices in the United States Since 1856. New York; National Bureau of Economic Research.

Mackowiak, B., 2007. External shocks, U.S. monetary policy and macroeconomic fluctuations in emerging markets. Journal of Monetary Economics, 54, 2512-2530.

Meuldijk, J., 1940. Der englische Schiffbau w“ahrend der Periode 1870-1912 und das Problem des Ersatzbaues. Weltwirtschaftliches Archiv, 52, 524-549. In Klovland (2004)

Miron, J.A. and Romer, C.D., 1990. A new monthly index of industrial production, 18841940. The Journal of Economic History, 50(2), 321-337.

Mullineaux, D., 1980. Unemployment, industrial production, and inflation uncertainty in the United States. The Review of Economics and Statistics, 62 (2), 163-169.

Ravazzolo, F. and Rothman, P., 2012. Oil and U.S. GDP: A Real-Time Out-of-Sample Examination. Journal of Money, Credit and Banking, 45(2-3), 449-463.

Ravazzolo, F., T. Sveen and S. K. Zahiri (2016), "Commodity Futures and Forecasting Commodity Currencies”. CAMP working paper 7/2016.

Radetzki, M., 2006. The anatomy of three commodity booms. Resources Policy, 31, 56-64.

Ratti, R.A. and Vespignani, J.L., 2013. Why are crude oil prices high when global activity is weak? Economics Letters, 121(1), 133-136.

Rossiter, J., 2010. Nowcasting the global economy. Bank of Canada Discussion Paper 12.

Steindel, C., 2004. The relationship between manufacturing production and goods output. Current Issues in Economics and Finance, Federal Reserve Bank of New York, vol. 10.

Stopford, M., 1997. Maritime Economics. 2nd ed. London: Routledge.

Stout, B.A, 2012. Handbook of Energy for Wold Agriculture.

Tinbergen, J., 1959. Tonnage and Freight. In Jan Tinbergen Selected Papers, 93-111. NorthHolland, Amsterdam in Klovland (2004).

Timmermann, A., 2006. Forecast combinations. Vol. 1 of Handbook of Economic Forecasting. Elsevier, 135 - 196.

World Economic Outlook, The international Monetary fund (IMF) 2014. Recovery Strengthens, Remains Uneven. 
Zarnowitz, V., 1987. The regularity of business cycles. NBER Working Papers 2381, National Bureau of Economic Research, Inc. 
Table 1: Forecasting world detrended real GDP

\begin{tabular}{|c|c|c|c|c|c|c|c|c|}
\hline Hor & 1 & 2 & 3 & 4 & 5 & 6 & 7 & 8 \\
\hline AR & 0.017 & 0.065 & 0.134 & 0.211 & 0.284 & 0.347 & 0.402 & 0.455 \\
\hline Kilian’s rea & $0.695^{*}$ & 0.708 & 0.693 & 0.715 & 0.747 & 0.763 & 0.781 & $0.816^{*}$ \\
\hline OECD IP & 0.828 & 0.922 & 1.030 & 1.131 & 1.218 & 1.287 & 1.332 & 1.355 \\
\hline Steel Prod. & $0.734^{* *}$ & 0.732* & $0.687 *$ & $0.664^{*}$ & 0.710 & 0.828 & 0.948 & 1.014 \\
\hline $\begin{array}{l}\text { FC_EW } \\
\text { FC SPE }\end{array}$ & $\begin{array}{l}0.599 * * * \\
0.596 * * *\end{array}$ & $\begin{array}{l}0.612 * * * \\
0.609 * * *\end{array}$ & $\begin{array}{l}0.627 * * \\
0.605^{* *}\end{array}$ & $\begin{array}{l}0.671 * * * \\
0.624 * * *\end{array}$ & $\begin{array}{l}0.739 * * \\
0.680^{* *}\end{array}$ & $\begin{array}{l}\text { 0.811* } \\
0.762 *\end{array}$ & $\begin{array}{l}0.876 \\
0.837\end{array}$ & $\begin{array}{l}0.920 \\
0.884\end{array}$ \\
\hline
\end{tabular}

Note: The table reports the Mean Square Prediction Error of the various alternative models to predict World detrended GDP over the sample 2000Q1-2013Q1. The column "AR" reports the MSPE value for the AR(1) benchmark model; the other columns present the ratio of the alternative model's MSPE to the benchmark's MSPE. Bold numbers indicate the alternative model provides lower MSPE. The alternative models refer to AR(1) model extended with one of the monthly indicators of global real economic activity studied in the paper and combinations of them based on equal weights (FC_EW) or inverted square prediction errors (FC_SPE). We measure statistical significance relative to the benchmark model using the Clark and West (2006) tests for equality of the average loss. One star * indicates significance at $10 \%$ level; two stars ** at $5 \%$ level; and three stars *** at $1 \%$ level. 
Table 2: Forecasting commodity prices: MSPE

\begin{tabular}{|c|c|c|c|c|c|c|c|c|c|c|c|c|}
\hline \multicolumn{13}{|c|}{ a) Crude oil prices (energy) } \\
\hline Series/time & 1 & 2 & 3 & 4 & 5 & 6 & 7 & 8 & 9 & 10 & 11 & 12 \\
\hline$\overline{\mathrm{AR}}$ & 7.085 & 71.245 & 71.354 & 71.497 & 71.2066 & 68.4496 & 69.83766 & $36.571 \epsilon$ & 67.0877 & 71.20371 & 1.271 & 73.243 \\
\hline Kilian & .035 & 1.024 & 1.027 & 1.035 & 1.043 & 1.050 & $\begin{array}{ll}1.057 & 1 .\end{array}$ & 1.082 & 1.035 & 0.988 & 1.038 & 1.039 \\
\hline OECD IP & 0.999 & 0.988 & 0.997 & 1.044 & 1.034 & 1.040 & $1.024 \quad 1$. & 1.046 & $1.018 \quad \mathrm{o}$ & $0.942 * 1$ & 1.003 & 0.986 \\
\hline Steel Prod. & $0.984 *$ & 0.972 & 0.955* & 0.988 & 1.008 & 1.023 & $1.022 \quad 1$. & 1.036 & $1.018 \quad \mathbf{0}$ & $0.935 * 1$ & 1.008 & 1.007 \\
\hline E & 85* & 0.997 & 0.987 & 1.018 & 1.030 & 1.034 & $1.031 \quad 1$. & 1.058 & 1.020 & 0.954 & 1.016 & 1.007 \\
\hline SPE & 85* & 0.997 & 0.988 & 1.019 & 1.030 & 1.034 & $1.030 \quad 1$ & 1.057 & 1.020 & 0.954 & 1.016 & 1.007 \\
\hline \multicolumn{13}{|c|}{ b) Natural gas prices (energy) } \\
\hline Series & 1 & 2 & 3 & 4 & 5 & 6 & 7 & 8 & 9 & 10 & 11 & 12 \\
\hline $\mathrm{R}$ & 104.121 & 109.211 & 1106.686 & 6100.326 & 2699.628 & 9.672 & 99.6009 & 97.179 & 98.9141 & 100.2179 & 94.576 & 94.00 \\
\hline lian & 0.988 & 0.980 & 1.011 & 1.025 & $5 \quad 0.990$ & 1.003 & 1.035 & 1.059 & 1.011 & 1.024 & 1.025 & 1.034 \\
\hline ECD IP & $0.955^{*}$ & 0.926 & 0.976 & 1.061 & $1 \quad 0.940$ & 0.963 & 0.998 & 1.020 & 1.010 & 1.025 & 1.002 & 1.004 \\
\hline eel & 96 & 0.960 & 1.001 & 0.995 & 0.978 & 0.980 & 1.007 & 1.029 & 1.006 & 1.030 & 1.010 & 1.002 \\
\hline C_EW & $64 * *$ & $0.938 *$ & 0.989 & 1.041 & 10.957 & 7 0.971 & 1.009 & 1.025 & 1.005 & 1.017 & 1.008 & 1.007 \\
\hline _SPE & $64 * *$ & $0.937 *$ & 0.989 & 1.039 & 0.956 & 0.971 & 1.008 & 1.025 & 1.005 & 1.016 & 1.007 & 1.006 \\
\hline \multicolumn{13}{|c|}{ c) Gold (precious metals) } \\
\hline eries & 1 & 2 & 3 & 4 & 5 & 6 & 7 & 8 & 9 & 10 & 11 & 12 \\
\hline$\overline{\mathrm{AR}}$ & 17.497 & 17.669 & 17.239 & $7 \quad 17.099$ & $\begin{array}{ll}9 & 17.34 \\
\end{array}$ & $41 \quad 16.55$ & 5616.679 & 916.587 & 716.396 & 16.237 & 16.331 & 17.344 \\
\hline iliar & 0.992 & 0.987 & 0.986 & 0.973 & 0.96 & 1.02 & $27 \quad 0.991$ & 10.981 & 10.973 & 0.982 & 0.981 & 0.987 \\
\hline ECD IF & 1.008 & 1.021 & 1.012 & 0.996 & 0.98 & 1.04 & $47 \quad 0.991$ & $1 \quad 0.994$ & 41.002 & $0.973 *$ & 1.007 & 0.998 \\
\hline Steel Prod. & 0.998 & 1.017 & 1.019 & 0.995 & 0.98 & 1.03 & $35 \quad 0.999$ & $\begin{array}{l}9.998 \\
\end{array}$ & 8.989 & 1.010 & 0.979 & 1.015 \\
\hline C_EW & 0.996 & 0.999 & 0.996* & 0.974* & ** 0.970 & $0 * 1.03$ & 34 0.981* & * 0.984 & $40.984 *$ & $0.971^{* *}$ & 0.983 & 0.987 \\
\hline SPE & 0.996 & 0.999 & $0.997^{*}$ & " $0.975 *$ & ** 0.970 & 0* 1.03 & 34 0.981* & * 0.984 & $40.984 *$ & ${ }^{*} 0.971^{* *}$ & 0.985 & 0.987 \\
\hline \multicolumn{13}{|c|}{ d) Fertiliser } \\
\hline ries/ti & 1 & 2 & 3 & 4 & 5 & 6 & 7 & 8 & 9 & 10 & 11 & 12 \\
\hline & 27.812 & 37.237 & 39.996 & 42.040 & 43.916 & 46.175 & 46.107 & 43.785 & 43.554 & 41.003 & 41.083 & 41.08 \\
\hline liar & 0.980 & 0.976 & 0.971 & 0.960 & 0.949 & 0.945 & 0.964 & 0.988 & 1.000 & 1.015 & 1.000 & 1.004 \\
\hline ECD IP & 0.994 & 0.973 & 0.938* & $0.960 *$ & 0.952* & 0.883 & 0.959 & 0.954 & $0.955^{* *}$ & 0.978 & 0.966 & 0.965 \\
\hline Steel Prod. & 0.992 & 0.994 & 0.978* & 0.981 & $0.932 *$ & $0.916^{*}$ & 0.960 & 0.951 & 1.007 & 1.014 & 0.981 & 0.974 \\
\hline EW & 0.983 & $0.955 * 0$ & $0.926 *$ & $.949^{\prime}$ & $.939 * *$ & * 0.896 & $0.952 * 0$ & 0.961* & 0.970* & 0.989 & 0.979 & 0.981 \\
\hline C_SPE & 0.983 & $0.955 * 0$ & $0.927^{*}$ & 0.94 & ** & * 0.897 & $0.952 * 0$ & $0.961^{*}$ & $0.969 *$ & 0.989 & 0.979 & 0.980 \\
\hline
\end{tabular}

Note: The table reports the Mean Square Prediction Error of the various alternative models to predict World detrended GDP over the sample 2000Q1-2013Q1. The column "AR" reports the MSPE value for the AR(1) benchmark model; the other columns present the ratio of the alternative model's MSPE to the benchmark's MSPE. Bold numbers indicate the alternative model provides lower MSPE. The alternative models refer to AR(1) model extended with one of the monthly indicators of global real economic activity studied in the paper and combinations of them based on equal weights (FC_EW) or inverted square prediction errors (FC_SPE). We measure statistical significance relative to the benchmark model using the Clark and West (2006) tests for equality of the average loss. One star * indicates significance $10 \%$ level; two stars ** at $5 \%$ level; and three stars *** at $1 \%$ level. 
Figure 1: World steel production and world real GDP: 1990Q1 to 2013Q3

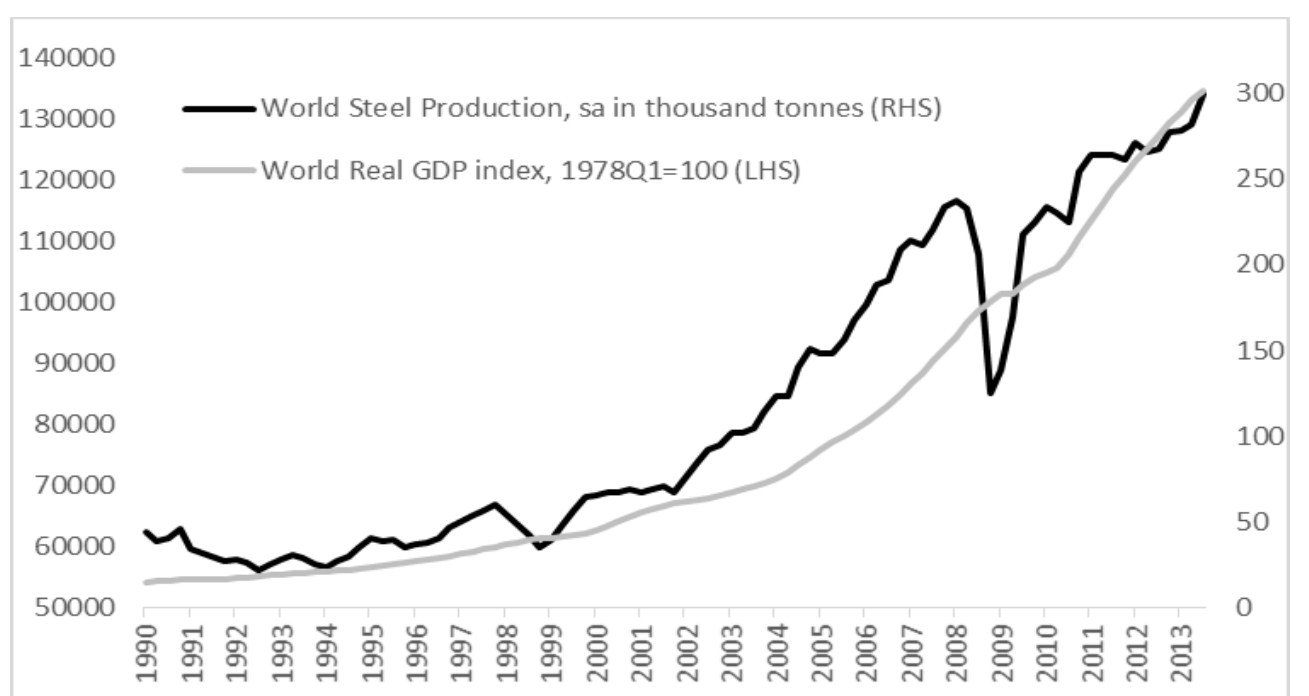

Note: The wolrd steel production serie has been seasonally adjusted by the authors using census X12 method.

Figure 2: Oil, gas, gold and fertilizer price indexes $(100=1990)$, monthly series: $1990 \mathrm{M} 1$ to 2016M12

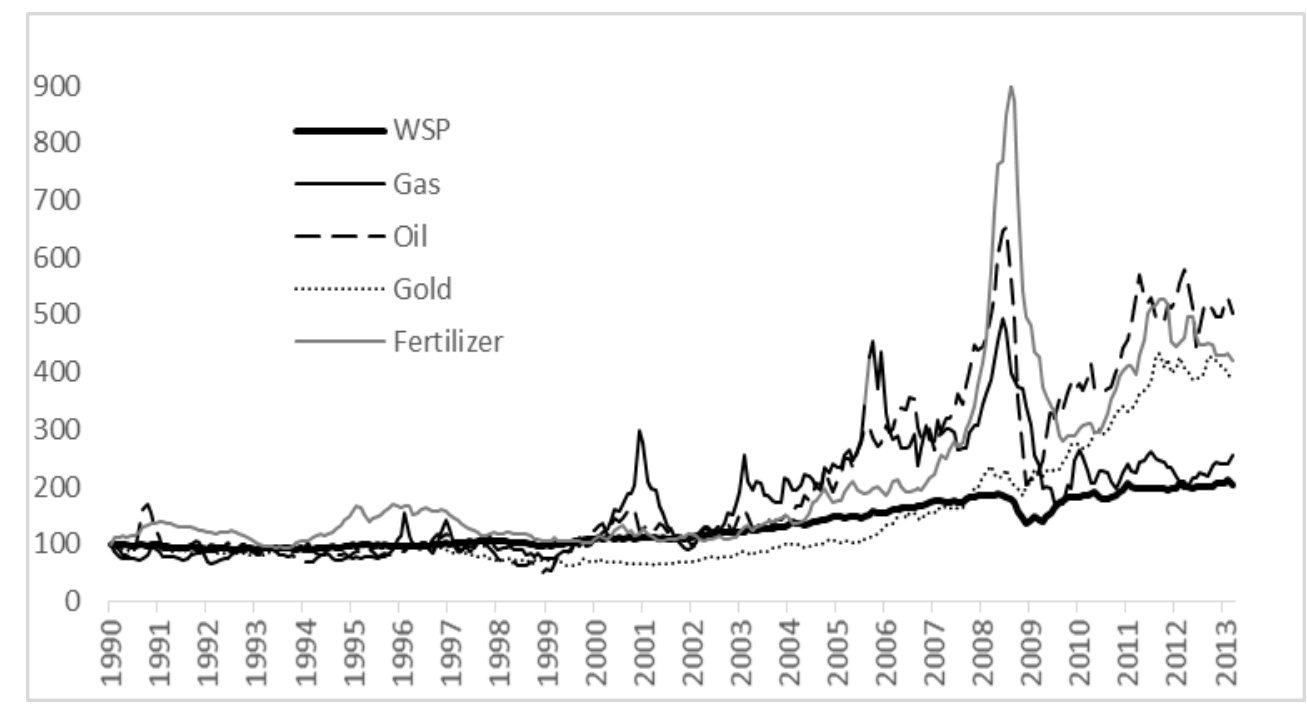


Figure 3: Giacomini and Rossi (2010) fluctuation test for equal out-of-sample predictability at $\mathrm{h}=1$

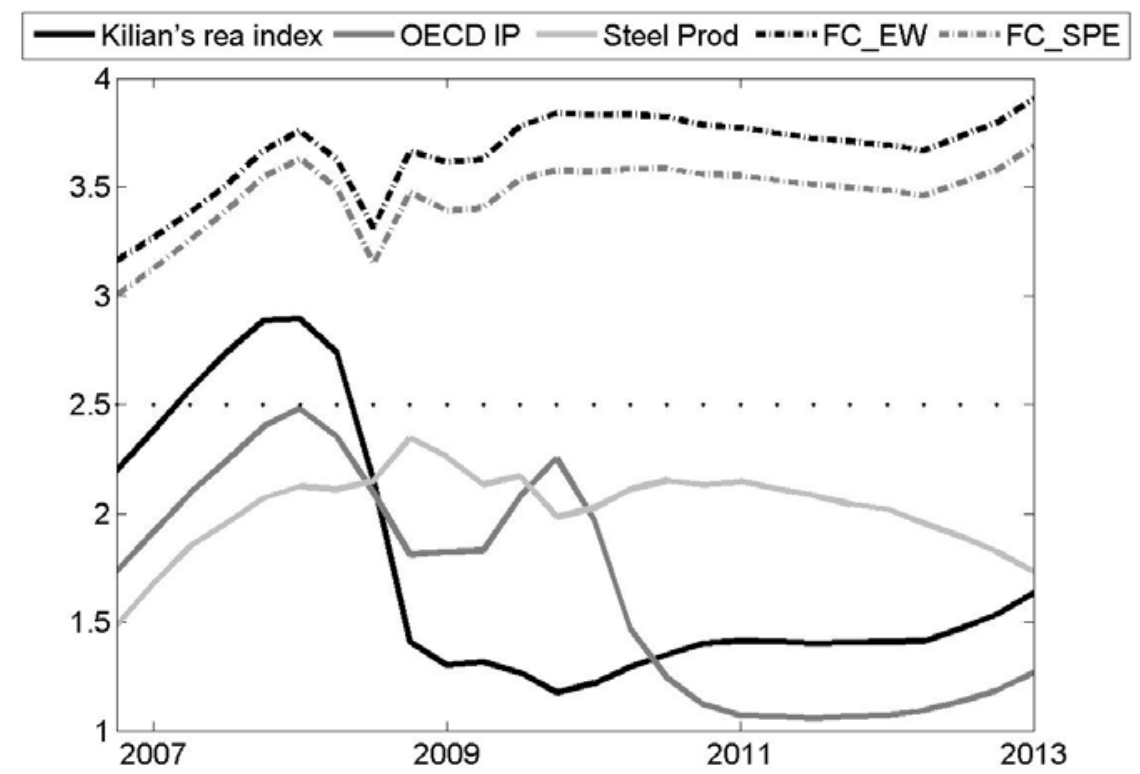

Note: Giacomini and Rossi (2010) Fluctuation test based on sequences of Clark and West (2007) test statistics (for testing equality of the average loss of the alternative models and the benchmark model), with $\mu=0.5 \mathrm{and} \mathrm{m}=\mathrm{P}$, where $\mathrm{m}=$ the size of the rolling window of $\mathrm{CW}$ statistics and $\mathrm{P}=$ the number of OOS observations, for the OOS period 2000Q1-2013Q1, such that the length of each window of CW statistics is 28 quarters, i.e., 7 years. The xaxis refers to the last value of each sample. Fluctuation test critical value at the $10 \%$ significance level in dotted lines; if the Fluctuation test statistic exceeds the critical value, the null that the benchmark model is the true model is rejected for the particular window. Benchmark model is an AR(1), alternative models in legend are defined in Section 6.

Figure 4: Giacomini and Rossi (2010) Fluctuation Test for Equal Out-of-Sample Predictability at $\mathrm{h}=8$.

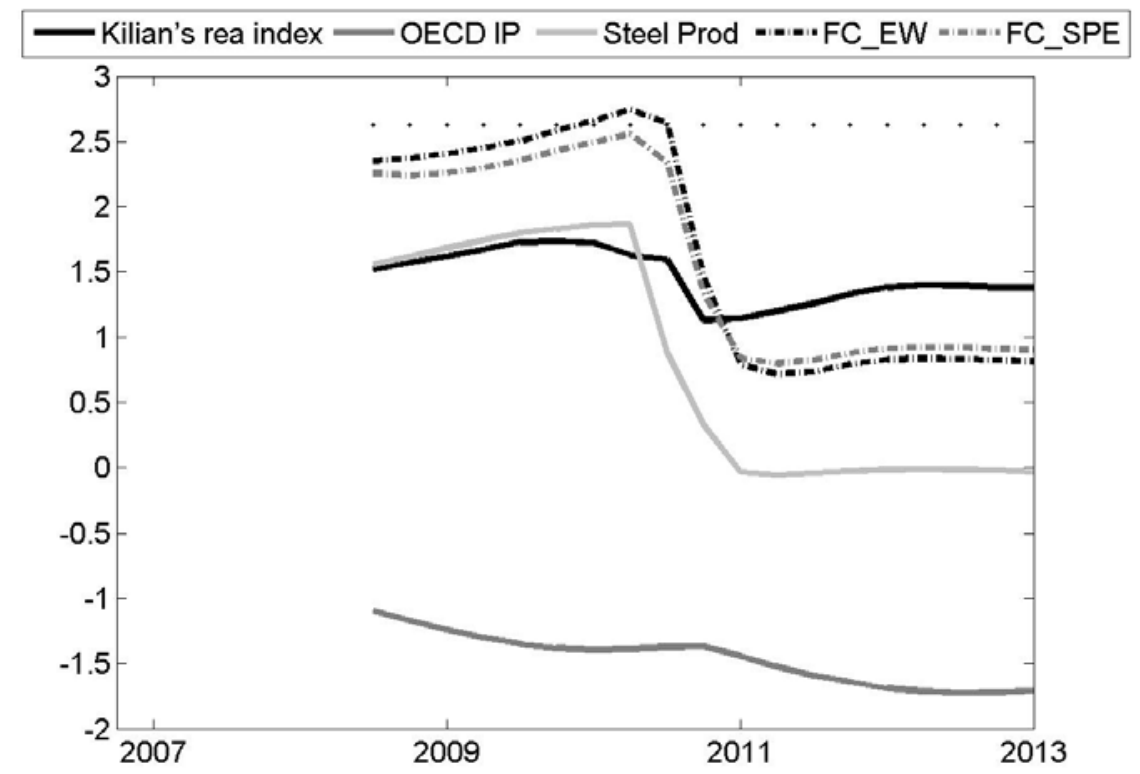

Note: See Figure 2. 